\title{
FORMULAÇÃO ESPECULATIVA DO PENSAMENTO TRANSCENDENTAL: A DIALÉTICA ENQUANTO RADICALIZAÇÃO DO PENSAMENTO TRANSCENDENTAL
}

\author{
Manfredo Araújo de Oliveira*
}

SÍNTESE - Klaus Hartmann interpreta a Dialética como uma radicalização do pensamento transcendental. A opção ontológica, tal como ela é feita pelo autor, significa que o método transcendental transborda, sai de seus limites clássicos, sai de si mesmo e se constitui como filosofia dialética. As categorias, ligadas umas às outras por relaçōes de negação, só possuem fundamento e legitimação enquanto são mediadas por um grande "sujeito conclusivo", que é o próprio pensamento enquanto idéia absoluta.
ABSTRACT - Klaus Hartmann interprets Dialectics as a radicalization of the transcendental thought. The ontological option made by the author implicates that the transcendental method becomes transcurrent, that it transpasses its own classic borders and constitutes itself as a Dialectic Philosophy. Categories - each of them is linked to all the others through the relationship of negation - are mediated through a big "conclusive subject" which is thinking itself as the absolute idea.

\section{KLAUS HARTMANN: A dialética enquanto "opção ontológica"}

\section{1 - A categorialidade do pensamento}

K. Hartmann tem como preocupação primeira esclarecer o lugar que a dialética ocupa no quadro das propostas filosóficas do mundo contemporâneo. Se a validade da metafísica é sempre questionável, '⿳a dialética, contudo, levanta a preten-

* Universidade Federal do Ceará - UFCE

- Metafísica, para Hartmann, tem a ver com a posição de existência de fundamentos transcendentes últimos, que pode muito bem ter significação para satisfação intelectual e existencial, mas cuja validade é sempre questionável porque tal posição fala de existentes sem a mediação ou separadamente do pensamento, o que seria propriamente a postura da representação. Cf.: HARTMANN Kl., Hegel: a non-metaphysical view, in: Hegel. A Collection of critical essays, ed, por Macintyre A, New York, 1972, p.118: "The solution, subtle thougt it is, is non-committal metaphysically, if not misread in the fashion of picturing (or "Vorstellung"), which asks for an existence apart from thought" Cf.: tb.: Hartmann Kl., Die ontologische Option, in: Die Ontologische Option. Studien zu Hegels Propädeutik, Schellings Hegel-Kritik und Hegels Phänomenologie des Geistes, Berlin, 1976, p. 1.

\begin{tabular}{|l|l|l|l|l|l|}
\hline VERITAS & Porto Alegre & v. 42 & $\mathrm{n}^{2} 4$ & Dezembro 1997 & p. 831-844 \\
\hline
\end{tabular}


são de ser ontologia enquanto "doutrina das categorias", ${ }^{2}$ o que a faz, radicalmente, diferente da ontologia clássica, ${ }^{3}$ pois aqui se põe, em primeiro plano, a problemática da fundamentação teórica, portanto, da legitimação de suas pretensões de validade. ${ }^{4}$ Para ele, foi precisamente Hegel que abriu ao pensamento filosófico esta concepção de ontologia ${ }^{5}$ de tal modo que sua própria concepção se articula nas vizinhanças de Hegel. ${ }^{8}$

A primeira característica da dialética é a categorialidade do pensamento, isto é, a pretensão de articular em conceitos o que o real é, ${ }^{7}$ o que significa, por um lado, romper a redução kantiana do pensamento à esfera dos fenômenos, sem, contudo, reconstituir a metafísica no sentido que a tradição a concebeu. ${ }^{B}$ A pretensão implica, em primeiro lugar, afirmar que é possivel pensar e dizer o que algo é de tal modo que uma "pesquisa conceitual" é uma "pesquisa do

2 Cf.: HARTMANN Kl., Hegel: a non-metaphysical view, op. cit., p.104.

3 O que é, aqui, comum é a pretensão de uma apropriação do real pelo pensamento. Cf.: HARTMANN Kl., Hegel: a non-metaphysical view, op. cit. p. 103. No entanto, Hartmann defende a tese de que Hegel nem sempre foi fiel a esta concepção de uma ontologia categorial, mas fez concessões a consideraçōes "existenciais (Cf. p. 119).

4 O que significa dizer que a ontologia pretendida por Hegel é, transcendentalmente, mediada: para Hegel a categoria é um conceito capaz de mostrar (o que pressupōe fundamentação) sua validade e, precisamente, por esta razão ele serve de princípio para o conhecimento da realidade.

5 Trata-se de uma ontologia enquanto teoria das categorias. Hartmann sabe que tem predecessores nesta interpretação categorial do pensamento de Hegel. Ele cita, expressamente, sobretudo a obra de R. Kroner, Von Kant bis Hegel, onde ele, segundo Hartmann, oferece uma análise sistemática da Lógica e de sua relação com a Fenomenologia do Espírito. São citados ainda H. Wagner, W. Flach e D. Henrich et alii, in: Hegelstudien, Beiheft 1, 1964. Cf.: K. HARTMANN, Hegel, op. cit. p. 116.

6 Distanciando-se de uma doutrina das categorias como, por exemplo, a de N. Hartmann em sua ontologia, porque simplesmente intuitiva e porque as fronteiras com a metafísica aqui não são claras, e aproximando-se das posições transcendentais de H. Wagner e W. Cramer. Neste sentido, Hartmann se afasta de qualquer interpretação historicizante do pensamento hegeliano, pois isto seria um retorno à metafisica. Cf. HARTMANN Kl., Hegel, op. cit. p. 122: "the Logic is not historical thought, it is systematic thought Philosophy is historical in that it reconstructs a richness that is historical, and it is historical in that it is transient, provided that history changes so as to demand a new philosophy. And yet, in all this, philosophy is systematic".

7 O que não significa fazer o que, segundo Hartmann, é o que aconteceu com o pensamento de Marx, que se deva confundir dialética e representação, dialética e concretização sensivel. Para Hartmann, a dialética hegeliana, que lhe serve de paradigma, não exige continuidade real exemplar, mas ordena temas ou categorias segundo uma arquitetônica. A disposição e a progressão das categorias decorrem, estritamente, do horizonte arquitetônico dos principios. Ao contrário, a dialética marxiana tem que levar em conta um motivo nominalistico, intuitivo e realistico. O problema, portanto, fundamental do pensamento de Marx, é, segundo Hartmann, o da confusão de niveis. Cf.: HARTMANN Kl., Hegel, op. cit. p. 115: "Hegels categorial theory, on the other hand, can "place" Marx's counterrecipe and show it to be a category mistake namely, the mistake of regarding an abstract categorial level as a concrete level that, to add to the paradox, is supposed to be the realization of the concrete categorial level". Cf. tb: HARTMANN Kl., Die Marxsche Theorie. Eine philosophische Untersuchung zu den Hauptschniften, Berlin, 1970, p. 415 e ss.

\& K. Hartmann interpreta a filosofia de Hegel como uma terceira posiçäo em contraposição ao espiritualismo metafísico e seu opositor o materialismo. Cf. HARTMANN Kl., Hegel: A non-metphysical view, op. cit. p. 102.

s Para Kl. Hartmann, Hegel não trabalha com qualquer conceito, mas, precisamente, com aqueles conceitos que levantam a pretensão de serem casos de integração entre determinações do ser e determinações do conceito. Então, categoria é o conceito que levanta a pretensão (Aristóteles), e a demonstra (Hegel), de ser sintese entre ser e pensamento. A doutrina aristotélica das categorias, já, apresenta as categorias com a pretensão de serem os princípios últimos para conceituar o ente 
ser" ${ }^{10}$ Precisamente conceitos que levantam a pretensão de ser a "unidade entre ser e conceito" se chamam "categorias"."

Ora, filosofia é a tematização de categorias, que sem ela são empregadas de modo inconsciente, não fundamentado e qualquer pretensão de conhecimento, em última instância, implica uma pesquisa categorial enquanto tematização dos princípios de todo e qualquer conhecimento como resposta à questão da legitimação do conhecimento. ${ }^{12}$ Precisamente, aqui, se situa a diferença com 0 conhecimento empírico: ${ }^{13}$ a filosofia tematiza os princípios a partir de onde conhecemos a realidade, ${ }^{11}$ ou seja, sua problemática central é a questão da validade.

Foi assim que Hegel concebeu as categorias de tal modo que sua pretensão é que o ser é assim como elas dizem. ${ }^{15}$ A pretensão categorial implica uma pretensão "transcendental", ${ }^{16}$ ou seja, um conceito é categoria quando não se pressupõe, mas se demonstra sua validade. O método de exposição das categorias é, ao mesmo tempo, fundamentação destas categorias. ${ }^{17}$ Categorias são, então,

enquanto ente. Hegel fornece a demonstração que faltou em Aristóteles. Cf.: HARTMANN Kl., Zur neuesten Dialektik-Kritik, in: Arch. f. Gech. u. Phil. 55 (1973) vol. 1, p. 234.

10

Tal posição implica a superação do nominalismo moderno na medida em que afirma que as verdades aprióricas são "ontológicas", ou seja, que não são apenas princípios do pensar e do falar, mas princípios do ser, o que implica que pensar e ser näo são dois mundos, simplesmente, contrapostos e, dicotomicamente, postos um ao lado do outro. Entender a dialética como ontologia significa dizer que os princípios do pensar e do falar constituem as "estruturas fundamentais do real". Hartmann parece nảo ter tirado todas as conseqüências desta tese básica para pensar a relação entre lógica e filosofia do real, como se vai mostrar depois.

1 Cf.: HARTMANN Kl., Hegel: a non-metaphysical view, op. cit. p. 108: "A category is the claim that being matches what thought thinks of it. We could not account for being in terms other than those of thought".

12 Esta reconstrução tem a pretensão de satisfazer a razão. Cf.: HARTMANN Kl., Hegel:a nonmetaphysical view, op. cit. p. 103: "It is a procedure to link up categories so as to let them result in a system that satisfies reason, i. e., which integrates any major determination of the real in a reconstructive scheme".

13 Para Hartmann, uma boa parte das objeçöes feitas a Hegel provem do desconhecimento do que uma teoria transcendental ou dialética pode ou não pode e de sua diferença com o saber empíricodescritivo. Cf.: HARTMANN Kl., Hegel, op. cit. p. 121.

14 A realidade só nos é dada pela mediação das categorias de tal modo que não tem sentido falar de "aplicação" das categorias aos objetos, ou na expressão de Hegel (Enz. \& 30,46, 48) "a sujeitos já dados prontos", como é o caso do "universal abstrato" separado da realidade. Cf.: HARTMANN $K l$., Zur neuesten Dialektik-Kritik, op. cit. p. 235.

15 A exposição categorial não é 'um mero jogo da razão consigo mesma' como disse Feuerbach de Hegel, mas exatamente a reconstrução racional da experiência. Cf.: HARTMANN Kl., Hegel: a nonmetaphysical view, op. cit. p. 103: “...his aim is to transform what is 'found', waht is 'experienced fact', into a 'presentation and reconstruction' (Nachbildung) of thought in terms of thought (Enc. \& 12)". Trata-se, para Kl. Hartmann, de uma reconstrução na forma de uma necessidade racional, ou seja, a priori.

16 Assumir o caráter transcendental do pensar significa dizer que filosofia não é uma consideração direta dos objetos da experiência, mas reflexão, isto é, retomo do saber de sua exteriorização no mundo na direção da subjetividade, onde o mundo se constitui. A filosofia parte da vida na direção da busca de legitimação da própria vida. Ela è transcendência a partir da vida para a tematização dos critérios de validade das atividades da vida humana. A pergunta da filosofia é a "pergunta pela legitimação" de nossa vida. Cf.: WAGNER H., op. cit. p. 61 e ss.

17 Hartmann reconhece que o procedimento hegeliano pode provocar a impressão enganadora, apesar da posição clara de Hegel, de que se trata de um processo real e aqui está a raiz da motivação que conduziu à reviravolta nominalístico-realista do pensamento dialético. Cf.: HARTMANN K1., Die Marxsche Theorie, op. cit. p. 451. 
"principios de validade", a expressão da racionalidade do real: elas são princípios de fundamentação de nosso conhecimento da realidade. ${ }^{18}$

Mede-se a diferença das categorias de outros conceitos a partir de sua possibilidade de inserir-se numa "conexão"19 dos princípios necessários de nosso conhecimento, ${ }^{20}$ portanto, se trata de tematizar formas de vinculação de conceitos, de relações entre conceitos, numa palavra, de expor a "auto-organização lógica"21 das categorias, onde é importante distinguir, em primeiro lugar, o conceito que é "ponto de partida", ou seja, aquele que não contém pressuposições, que recorrem a conceitos a serem ainda explicitados e, por esta razão, é mais pobre, ou seja, um começo sem pressupostos, neste sentido abstrato, não verdadeiro.

Em segundo lugar, é necessário pensar o próprio "desenvolvimento categorial", o curso da exposição categorial de tal modo que sua ordenação possa fazer aparecer a "função de princípio" de determinados conceitos em relação a outros conceitos mais concretos e em relação a conceitos da experiência e das ciências empíricas, de tal modo que fique claro que a dialética é uma progressão conceitual, que seu objetivo é a explicação da verdade do real, assim que cada passo do pensamento deve ser uma recepção parcial e uma integração do ser no pensamento $^{22}$ e não uma "descrição" de uma continuidade real. A relação entre abstrato e concreto, não verdadeiro e verdadeiro, decorre de uma arquitetônica orientada por princípios: o progresso linear é orientado arquitetonicamente. Os degraus de determinação superior são ordenados a constelações de princípios superiores. ${ }^{23}$

Por fim, o "conceito conclusivo" deve ser um conceito que contenha, de modo pleno, a unidade de ser e conceito, ou seja, ele deve manifestar em si mesmo a realização da categorialidade do conceito, a razão consciente de si mesma, a imanência de todas as determinidades do ser no pensamento. ${ }^{24}$ Este conceito con-

${ }^{18}$ É neste sentido que, para Hartmann, a intenção fundamental de Hegel é fornecer uma "teoria da determinidade dos conceitos", ou seja, uma teoria em que devem ser explicitadas as relações entre conceitos através da reconstrução de determinidades com um procedimento que não se baseia em pressupostos. Neste contexto, a primeira coisa é explicitar a "genealogia" do determinado, isto é, mostrar que o compreendido através de antecedentes é um resultado a partir da oposição, que é expressa pela negação. Nesta perspectiva, a negação, enquanto relaçāo entre conceitos, é o meio de pensamento através de que se pode apresentar a determinidade de conceitos.

Porém de forma alguma como uma deduçăo. Cf. HARTMANN Kl., Hegel: a non-metaphysical view, op. cit. p. 105: "The linear progression cannot be deduction, it can only be reconstruction; what it is heading for is granted".

O sistema dos pressupostos necessários do sentido e da argumentação válida é o que D. Wandschneider vai chamar de "Lógica Fundamental". Cf.: WANDSCHNEIDER D., Grundzüge einer Theorie der Dialektik. Rekonstruktion und Revision dialektischer Kategorienentwicklung in Hegels "Wissenschaft der Logik", Stuttgart, 1995, 18 e ss.

${ }_{21}$ De tal maneira que cada uma apareça como justificada em relação a sua precedente. Cf. HARTMANN Kl., Hegel, op. cit. p. 104-105: "This commits the reconstruction to a linear development, to a sequence or genealogy of categories, such that each item can be regard as 'justified' in view of its antecedents".

Para Kl. Hartmann, é isto que Hegel denomina "negação determinada", ou seja, aquela conjunção de uma oposição que põe como unidade concebida e, portanto, enquanto integrada, aquilo que resisitiu à integração e enquanto tal se apresentava como oposto, como outro ao pensamento. Cf.: HARTMANN Kl., Zur neuesten Dialektik-Kritik, op. cit. p. 226.

23 Para Hartmann, a estrutura básica da lógica hegeliana é a unidade complexa de linearidade, progressão e regressão e arquitetônica. Cf.: HARTMANN Kl., Hegel, op. cit. p. 106.

24

Cf. HARTMANN Kl., Zur neuesten Dialektik-Kritik, op. cit. p. 225. 
clusivo é um "absoluto"25 que, enquanto resultado do desenvolvimento categorial de onde ele provém, é penhor, garantia, fundamento de validade da categorialidade de todos os conceitos que o precederam e, neste sentido, "fundamentação última"26 de toda a exposição categorial. ${ }^{27}$

O ponto de vista especulativo do pensamento consiste precisamente na legitimação deste absoluto. ${ }^{28}$ Daqui depende a validade de toda a exposição categorial. O conceito conclusivo da exposição categorial é a própria categorialidade de tal modo que a transcendentalidade dos conceitos categoriais emerge como, intracategorialmente, legitimada através de seu ser pensado pela mediação de um "sujeito conclusivo": o pensamento enquanto idéia categorial ou absoluta. ${ }^{29}$ Esta é a "formulação especulativa do pensamento transcendental" de tal modo que a dialética é o pensamento transcendental ${ }^{31}$ levado às últimas conseqüências. A dialética emerge, assim, como o procedimento específico da reflexão filosófica, ou seja, em primeiro lugar, como o procedimento adequado para solucionar a questão da fundamentação última. ${ }^{32}$

${ }^{25}$ Para H. Wagner, o problema central da filosofia é o problema da completude da fundamentação, ou seja, da superação de um processo infinito de fundamentação, pois tal processo significa a negação de qualquer fundamentação, portanto, a negação da verdade. Por isto, a tarefa primeira e central da filosofia, enquanto, reflexão é resolver o problema da completude da fundamentação, isto é, da tematização do "chão absoluto" enquanto instância de fundamentação última., que ele denomina "positivamente Infinito, o Absoluto". Cf.: WAGNER H., p. 117 e ss.

Para Hartmann, a posição de Fichte e Schelling é uma posição alternativa à sua, ou seja, a de uma "ontologia categorial", porque eles pretendem chegar a uma teoria "não-categorial" da fundamentação última.

Para Hartmann, esta postura contém a combinação da exigência transcendental (legitimação dos conceitos) e o ponto de vista especulativo, ou seja, da demonstração completa da categorialidade, o que implica a tematização de uma esfera absoluta (fundamentação última). Isto é, da esfera de conhecimento não hipotético, incondicionado.

29 Para Hartmann, uma teoria da validade tem que ser construida na base de um "chão absoluto", mesmo, que, quando se ofereça a oportunidade, o sujeito fático seja incluído na teoria. No entanto, ela não acha legitima a tentativa de $\mathrm{H}$. Wagner de pensar facticidade e validade como complementares. Cf. HARTMANN Kl., Die ontologische Option, op. cit. p. 5, nota 13.

Esta postura de $\mathrm{K}$. Hartmann está na direção da reformulação do pensamento transcendental articulada por seu mestre H. Wagner. Para ele, a filosofia se compreende a si mesma como uma dupla tentativa de conciliação: a) Conciliação entre o motivo crítico e o especulativo, ou seja, entre Kant e Hegel. Motivo critico: a subjetividade finita tem que se provar a si mesma em todas as suas produções-Kant; motivo especulativo: esta prova só pode acontecer numa teoria especulativa, ou seja, na consciência do infinito e do absoluto; b) Conciliação entre principialidade (Neokantismo) e Facticidade (Fenomenologia). K. Hartmann tem objeçōes quanto ao segundo item, mas assume, plenamente, o primeiro. Cf.: WAGNER H., Philosophie und Reflexion, seg. ed, München-Basel, 1967, Prefácio da primeira edição.

31 Não há sinais no pensamento de Hartmann de transformação do pensamento transcendental a partir da reviravolta lingüistico-pragmática do pensamento contemporâneo. Sendo a dialética a radicalização do pensamento transcendental, a reviravolta lingüístico-pragmática não tem, conseqüentemente, significação na articulação da racionalidade dialética. No entanto, ele se confronta com a pergunta se a filosofia moderna da linguagem não poderia arranjar-se com uma ontologia categorial na linha por ele proposta. Cf.: HARTMANN Kl., Die ontologische Option, op. cit. p. 5, nota 13.

32 Cf.: HARTMANN Kl., Hegel, op. cit. p. 103: "The vehicle of reconstruction will be concepts or categories; the procedure will be the dialectic". 
O método ou o procedimento de exposição categorial não é, segundo Hartmann, dedutivo ${ }^{33}$ no sentido da gestação das categorias mais ricas a partir de categorias mais pobres, mas é uma "reconstrução" enquanto método de racionalização do que é encontrado. ${ }^{34}$ Assim, trata-se de um método "regressivo" no sentido de que se parte do encontrado ${ }^{35}$ e se retorna a algo a partir de onde ele pode ser reconstruído de tal modo que o princípio para a reconstrução e o resultado são afirmativos. O resultado é, portanto, fundamento e confirmação da reconstrução. Mostra-se, assim, uma totalidade, uma plenitude lógica e justamente não como um agregado de todos os conceitos de ser apresentados, mas de novo enquanto categoria, isto é, enquanto 'categoria do absoluto', em que o pensamento das categorias resume todas as categorias e em que, ao mesmo tempo, ele aparece como o resultado da doutrina das categorias.

Para Hartmann, é fundamental que o ponto alto das categorias é atingido através de um processo extraordinário de concretização de conteúdo, embora, de nenhum modo, se trate de "dedução de conteúdo". ${ }^{36}$ A filosofia emerge, então, como uma totalidade tanto do ponto de vista teorético-sistêmico, como do ponto de vista do conteúdo. Numa palavra, a filosofia é a totalidade de captação do ser, ela é uma totalidade de determinações normativas, justamente categoriais, do ser ou do real, ela é uma totalidade de ontologia transcendental ou especulativa. As

33 Uma das teses centrais da pragmática transcendental, em nossas dias, é que, precisamente, a reviravolta lingüístico-pragmática do pensar nos deu a possibilidade, o que nem sempre ocorreu em nossa tradição, de distinguir, com rigor, os procedimentos típicos das ciências-método hipotético-dedutivo e os da filosofia-reflexão. Cf.: APEL K.-O., Fundamentação última nāo-metafísica, in: Dialética e Liberdade, Festschrift em homenagem a Carlos Roberto Cirne Lima, ed. por Stein E./De Boni L. A., Porto Alegre/Petrópolis, 1993, p. 305-326. OLIVEIRA M. A. de, Sobre a Fundamentação, Porto Alegre, 1993, p. 68 e ss.

34 O que de si poderia implicar uma dialética entendida não como uma construção apriórica necessária, mas como uma dialética que implicaria uma tarefa hermenêutica, uma referência ineliminável à experiência e à história. Hartmann se reduz a abrir o espaço para uma reconstruçăo categorial permanente sem explicitar as conseqüências de uma tal concepção para a própria compreensão da dialética enquanto tal. Sua referência metodológica fundamental é, aqui, o parágrafo 12 da Enciclopédia de Hegel. Ai, Hegel afirma que a filosofia deve à experiência sua originação. Ela parte da experiência, isto é, da riqueza do conteúdo que se encontra na forma de algo "imediato" e "contingente" e sua tarefa específica é, negar esta forma e elevar o conteúdo à esfera da "necessidade". Numa palavra, o que a filosofia faz é elevar o encontrado na experiência ao nível do conceito. Este estimulo impele o pensamento a sair de uma universalidade abstrata e a desenvolver-se a partir de si. As ciências empíricas preparam este material particular para ser recebido pela filosofia, no qual ela vai detectar as determinações universais, os gêneros e as leis. Este acolher por parte da filosofia é ao mesmo tempo um desenvolver-se do pensamento a partir de si. No entanto, enquanto a filosofia tem a agradecer às ciências empíricas seu desenvolvimento, ela dá a seus conteúdos a forma essencialíssima da liberdade (do apriórico) do pensamento e a confirmação da necessidade. A respeito da relação entre experiência e pensamento no pensamento hegeliano Cf.: PUNTEL L. B., Darstellung, Methode und Struktur. Untersuchungen zur Einheit der systematischen Philosophie G. W. F. Hegels, seg. ed. Bonn, 1981, p. 248-250. Tanto Hegel como Hartmann tocam aqui uma questão central para a dialética, a que retornaremos neste trabalho: o elevar o dado, o encontrado ao nível do conceito significa articular uma dialética necessitarista, onde não há espaço para o contingente? O contingente é apenas ponto de partida que depois deve ser abandonado? Cf. sobre esta problemática: Hegel, Como o Senso Comum compreende a Filosofia seguido de a Contingência em Hegel de J.M. Lardic, Rio de Janeiro, 1995. 
determinações do ser captam para além da unidade substancial, como a tradição conheceu, realidades plurais como a familia, a sociedade e o Estado, nas quais se pode ver, também, uma unidade categorial.

Hegel concebeu a filosofia em primeiro lugar como lógica, que desemboca num absoluto do pensamento das determinações ontológicas, a idéia absoluta. Mas, de antemão, está prevista sua continuação na direção de maior concretude: a lógica se amplia na direção do sistema. Hegel considera a realidade como um oposto renovado ao pensamento, que já foi desenvolvido na lógica. Então, emerge uma nova tarefa para o pensamento: diferenciar-se categorialmente através da realidade e acolhê-la em si através da mediação de categorias, isto é, de categorias mais ricas, mais verdadeiras. O pensamento tem de desenvolver a partir de si, ou melhor, reconstruir categorias da natureza e do espírito enquanto de um espírito na exterioridade do real, portanto, tem que chegar às determinações da filosofia do real.

Quando se conclui este segundo ciclo categorial, o ciclo da filosofia do real e se conduz a uma totalidade de um novo degrau, o absoluto da filosofia, então, a filosofia enquanto doutrina das categorias, enquanto sistema, se completou, se abstraimos da filosofia da religião, da estética e, sobretudo, da filosofia da história, onde se explicita uma outra compreensão da realidade, não mais categorial, mas justamente metafísica e, onde, no caso da história, se levanta o problema de uma conclusão aberta.

\section{2-O princípio da dialética}

Em que consiste propriamente a especificidade da dialética, que a distingue de outras posturas com pretensão ontológica? Já sabemos que a exposição é categorial, isto é, pretende ser exposição de conceitos com relevância ontológica. ${ }^{37}$ Além disto, trata-se de uma exposição que estabelece relações entre categorias sob a pretensão de verdade ou validade: um tal conceito reconstruído não pode parar em si mesmo, na medida em que ele não é conclusivo ele é apenas relativamente verdadeiro e aponta para além de si mesmo até que se mostre o conceito conclusivo da pura categorialidade. ${ }^{38}$

A necessidade deste processo se manifesta a partir de uma mediação, que é condição de possibilidade para que o conceito possa emergir como determinado de tal ou tal modo: a "negação". Ela é um veículo fundamental para a reconstrução de um conceito enquanto determinado: trata-se da exclusão do outro de tal modo que condição de possibilidade da determinação de um conceito é a exclusão

37 Isto significa, para Hegel, a superação da postura básica da filosofia modema, que se articula na dicotomia entre sujeito e objeto, homem e mundo. O saber absoluto é exatamente a "superação" desta postura. Cf. a respeito: LUFT E., Para uma crítica interna ao sistema de Hegel, Porto Alegre, 1995, p. 62: "[...] ao mesmo tempo, o espírito resolve a cisão entre sujeito e objeto ao compreender que o seu lógos (a sua capacidade de se autodeterminar racionalmente) é também o lógos do mundo. $\mathrm{O}$ resultado é a identidade de ser e pensar, enquanto ambos são portadores e realizadores do mesmo lógos." changing over to for itself potential, thereby giving way to another category". 
de outro. ${ }^{39}$ É precisamente a negação que vincula um conceito com seu contraconceito e é em sua força que um conceito não pode permanecer em si mesmo, ${ }^{40}$ ou seja, sempre se exige algo novo para a solução da contradição detectada ${ }^{41}$ Um conceito não pode valer do mesmo modo que o outro, ambos se excluem reciprocamente enquanto a verdade total ou comum de algo. ${ }^{12}$

Ora aqui está precisamente a "raiz da dialética": ${ }^{43}$ ela é um procedimento de determinação conceitual ${ }^{44}$ que leva a sério a exigência de evitar a contradição ${ }^{45}$ (a negação da negação) para, através da negação, deixar apontar para adiante ${ }^{46}$ a determinidade indicada de conceitos. ${ }^{47} \mathrm{O}$ novo é o todo mais alto, a síntese de

${ }^{39}$ H. Wagner distingue dois tipos de contradição: a contradição que é eliminação de qualquer determinação e a contradição exigida para a determinação, ou seja, a relação necessária a outros predicados e os unifica no princípio de limitação. Cf.: WAGNER H., op. cit. p. 101 e ss.

De acordo com a compreensão de $\mathrm{H}$. Wagner da função positiva do princípio de limitação, pois a limitação realiza aquilo que a negação exige: a determinação através da posição de uma determinidade. A negação exige a determinação através da posição de uma determinidade: apesar de ela não ser determinada em si mesma, ela põe o objeto enquanto algo a ser determinado e enquanto determinável. A limitação põe, então, esta determinação possivel e exigida através da posição de um negativo: não-a. Cf.: WAGNER H., op. cit. p. 108.

41 É isto que E. Luft chama de "contradição por insuficiência". Cf.: LUFT E., op. cit. p. 83-84: "Por fim, a contradição por insuficiência é aquela que deve ser superada, sendo resolvida no nível superior da síntese. Essa contradição é sinônimo de insuficiência, ela demonstra um déficit fundamental que toma conta de todos os opostos, enquanto não devidamente sintetizados. Ela é na Lógica sempre resolvida, na medida em que todas as sinteses levam à sintese final, à idéia absoluta. A sua resolução nos levará à contradiçāo sintética."

42 É por esta razāo que, para Hartmann, uma teoria da determinidade de conceitos não pode satisfazer-se apenas com a indicação da relação de contrariedade entre conceitos. O caso contrário, para ele, sempre pressupõe um campo empírico de aplicação, onde podem perfeitamente conviver positividades não-disjuntivas e isto não conduz à determinidade dos próprios conceitos. Não se pode, portanto, de uma unificação empírica de contrários recorrer a uma relação conceitual pura e é disto que se trata na dialética.

Cf.: HARTMANN Kl., Hegel, op. cit. p. 109: “This replacement of othemess or novelty by negation in the service of comprehension is what is called the dialectic".

44 Hartmann é, aqui, influenciado pela concepção de conhecimento de H. Wagner. O conhecimento se realiza num juizo em que o objeto recebe uma determinação, que é fundamento de seu conhecimento. Ora no juízo a função do predicado é, precisamente, dizer o que o objeto è. Assim, o conhecimento se revela como um "evento de determinação" e sua questão central é a questão da determinidade do conceito predicativo. A dialética é uma proposta de resposta a esta questão básica. Cf.: WAGNER H., Philosophie und Reflexion, seg. ed., München/Basel, 1967, p. 93 e ss.

${ }^{45}$ Na mesma direção pensa E. Luft. Cf.: LUFT E., op. cit. p. 83, nota 222: “....Em Hegel, as contradiçōes por insuficiência são realmente aquilo que o lógos deve resolver, solucionar, e a sua solução é o movimento de autodeterminação do absoluto. Mas isto não diz nada contra este sistema teorético não contraditório; pelo contrário, a idéia básica é justamente a superação constante da contradição por insuficiência, na busca do não contraditório (evitando, assim, a contradição implosiva). Para Hartmann se faz necessário distinguir, claramente, entre dois casos: o da representação de um objeto no campo de aplicação de conceitos, onde não se faz necessário apontar para frente e o caso da imanência conceitual, onde este procedimento é essencial. Cf.: HARTMANN Kl., Zur neuesten, op. cit. p. 229.

47 Para H. Wagner, que é aqui a inspiração de Hartmann, é o princípio da "contradição exigida" que explica a determinação no conhecimento. Conhecimento só é possivel, quando há determinação do sujeito através do predicado. $O$ predicado, por sua vez, só pode ser determinado na medida em que se situa em relação a todos os outros predicados na perspectiva de diferença, de contradição, de exclusão. Um conceito predicativo a tem determinidade somente em relação a năo-a (o conjunto de todos os outros predicados). Assim, não-a é condição de possibilidade da determinação de a: a determinidade de cada predicado pressupõe a relacionalidade a todos os outros predicados, 
uma diferença até que se chegue a um todo último afirmativo. Com isto ela pretende fornecer uma progressão, que é explicação do verdadeiro, uma reconstrução categorial de todas as categorias até que se chegue a um conceito último que esteja acima das oposições, ${ }^{48}$ isto é, que tenha superado a contradição que, por um lado, é necessária pois não há determinação de um conceito sem que ele se distinga de todos os outros, mas, por outro lado, ela impede a solução da questão da determinação já que contradição significa pôr uma determinação e, ao mesmo tempo, eliminá-la. Assim, evitar a contradição é condição instranscendivel para a consecução da determinação.

Este conceito último deve ser tal que possa garantir a categorialidade de todos os conceitos precedentes e com isto fundamentar, em última instância, o conhecimento, o que significa que determinação só pode, realmente, acontecer no horizonte da totalidade dos conceitos. Considerando as coisas regressivamente, são escolhidos para a explicação, precisamente, aqueles princípios que têm o verdadeiro como meta até chegar ao conceito último que garante a verdade de todos os outros: a teoria termina num verdadeiro que é conclusivo, afirmativo a partir de onde é, regressivamente, determinada a solução dialética da contradição através do "princípio da limitação". ${ }^{99}$ Este conceito conclusivo é o "principio para os princípios" e dialética se constitui, então, como já em Platão, enquanto "Teoria dos Princípios". ${ }^{50}$

Com os meios de pensamento do ser e da negação, ${ }^{51}$ pode-se determinar suficientemente em que consiste a categorialidade do conceito: o não ser estranho do

ou seja, precisamente a relação de contradição, de exclusão. Portanto, a determinidade de cada predicado pressupõe o sistema de todos os predicados, que estão relacionados entre si, neste sistema, através do principio de exclusão, portanto, pela mediação da negação. Cf.: WAGNER H., op. cit. p. 103-104.

48 Para Hartmann, a dialética é reconstrução do encontrado na "ordem da compreensão", isto é, a partir do que não tem pressuposiçōes. O que é fundamental, aqui, é a "oposiçāo dialética", ou seja a oposição limitativa, o que faz com que o processo reconstrutivo não seja apenas entre relaçōes contrárias, isto é, oposições entre o que é somente positivo, o que não levaria à determinidade dos conceitos, pois esta exige disjunção, numa palavra não é possível atingir a determinidade de conceitos (e esta é a questão central da dialética) somente a partir do positivo. Então, na dialética, há lugar para a "contradiçăo" no sentido de que o conceito que concede determinidade a outro é negação em relação a ele. Portanto, uma teoria da determinidade de conceitos põe contradições entre determinidades positivas em disjunção, que são um terceiro, ou seja, não simplesmente oposiçôes contrárias, nem também só contraditórias, mas oposiçōes limitativas, enquanto unidade de oposições contrárias e contraditórias, gerando, assim, algo novo, próprio. Cf.: HARTMANN Kl., Zur neuesten Dialektik-Kritik, op. cit. p. 227-229.

49 Para H. Wagner, o "principio de limitação" é a soluçâo do problema da contradição (ela é necessária e, ao mesmo tempo, elimina qualquer determinação), porque, aqui, se mostra que um membro dos contraditónios é posto como determinação do objeto, o outro como condição de possibilidade desta determinação. Cf.: WAGNER H., op. cit. p. 109.

50 Cf. Hösle V., Wahrheit und Gechichte. Studien zur Struktur der Philosophiegeschichte unter paradigmstischer Analyse der Entwicklung von Parmenides bis Platon, Stuttgart/Bad-Cannstatt, 1984, p. 448 e ss . REALE G., História da Filosofia Antiga, vol. II, São Paulo, 1994, p. 83 e ss..

${ }^{51}$ A "negação" tem uma dupla mediação a exercer no procedimento dialético. Em primeiro lugar, ela é condição de possibilidade da determinação, que só pode ocorrer via exclusão. Mas, em segundo lugar, ela é condição de possibilidade do prosseguimento do procedimento expositivo, uma vez que é através dela que aparece a diferença entre o conceito em questão e a categorialidade pura, ou seja, que se detecta a contradição vigente entre a pretensão plena de categorialidade e as capacidades categoriais do conceito em questão. Hartmann sabe da objeção de D. Henrich a respeito 
ser em relação ao conceito se mostra na relação de negação entre conceito e ser, que através da negação da negação é reconduzido à unidade. A dialética não é, então, um simples encadeamento de conceitos através do emprego da negação, mas ela tem um caráter estritamente categorial, isto é, é um procedimento destinado a mostrar a validade de seus conceitos. Ela vincula, portanto, conceito e conceito e ser e conceito e ambas as vinculações entre si. ${ }^{52}$

\section{3 - A arquitetônica do pensamento dialético}

A dialética é teoria dos princípios, ela articula relações de principialidade: é possivel distinguir modos diferentes de integração entre ser e conceito e formulálos enquanto princípios para principiados. As formas primeiras de integração, na linguagem hegeliana as formas do ser, servem enquanto princípios para as captações explícitas destas formas em diferentes esferas. Então, a exposição dialética se articula, em primeiro lugar, como uma "lógica do ser" no seio da qual parece que um oposto se põe fora da determinidade do outro oposto e é trazido de fora; ela procede com a tematização de conceitos em que o oposto é inerente, ou seja, na linguagem de Hegel, com a "lógica da essência" até chegar à superação da relação de oposição na "lógica do conceito". Numa palavra, a exposição categorial percorre degraus de categorialidade e para Hartmann não se pode interpretar este

da impossibilidade da negação de ser o veículo da lógica da essência. No entanto, em sua opinião, o conceito de reconstrução ligado ao principio arquitetônico pode confrontar-se com a objeção de que a negação nāo pode ser a chave de reconstrução de toda a lógica. Cf.: HARTMANN Kl., Die ontologische Option, op. cit. p. 9, nota 22.

H. Wagner considera o problema central de toda a pesquisa dos princípios o problema da "relação dialética", portanto, no princípio da dialética se situa o problema central do conhecimento. Sua interpretação da relação dialética parte da distinção entre duas formas de oposição. No caso da oposição "analítica" os membros se excluem mutuamente entre si, um anula necessariamente o outro, pois existe, aqui, uma disjunção total de tal modo que é impossivel buscar um terceiro membro o que não é o caso na oposição "dialética", onde os membros são "espécies de um gênero". Ora o gênero para sua determinidade exige um outro gênero, que em virtude disto se põe em relação a ele em oposição analítica. Com isto revela-se a disjunção como incompleta, já que ambos os membros podem ser falsos; aliás eles têm que ser falsos, quando o outro membro é verdadeiro num plano mais elevado. Com isto, segundo $\mathrm{H}$. Wagner, se mostra que a contradição não é solúvel no mesmo nível e que só se chega à verdade através de uma subida das espécies para o gênero subjacente. A verdade das espécies está em seu fundamento comum, o gênero e a dialética se constitui como uma pirâmide de espécies e gêneros até que se chegue a um último, o absoluto, que tem determinidade não mais através do gênero oposto, mas através de algo por ele fundado, o predicado absoluto. Para Hartmann, Hegel pensa a dialética de modo diferente. Começamos com o indeterminado, o ser, que enquanto é compreendido como indeterminado é levado a uma determinidade. $O$ determinado se determina mais através de opostos, através da negação do determinado. Ora esta progressão de determinidades não é a do tipo de espécies e gêneros, pois a dialética não acontece entre qualquer espécie e seu complemento enquanto outro conceito de espécie, mas interpreta a oposição lógica como uma oposição dupla, ao mesmo tempo oposição entre conceito e conceito e oposição entre conceito e ser ou entre o ser relativamente indeterminado e a determinadade no conceito. As oposições que desta forma são tematizadas diferem das da dialética de gêneros e espécies, mesmo que a dialética de gêneros e espécies possa constituir um exemplo da dialética. Em Hegel há, numa progressão conceitual não linear, começo, desenvolvimento e retorno ao fundamento, enquanto uma dialética de gêneros e espécies se eleva de qualquer espécie para o fundamento sem oposição, sem poder estabelecer com segurança, que só há uma forma necessária de elevação. 
procedimento, como o faz $\mathrm{H}$. Wagner, como uma dialética de gêneros e espécies, ${ }^{63}$ mas se trata de uma organização arquitetônica no seio de uma reconstrução de relações ontológicas de unidade ou categorias com o auxilio do ser e da negação através de relações principiais de unidade como ocorre no seio da lógica na passagem da lógica do ser para a lógica da essência e do conceito, ou seja, trata-se aqui de uma "ordenação vertical", que Hartmann denomina" progressão transesférica".

Mas ele conhece, também, uma relação horizontal, pois dentro de cada esfera se põe a tarefa da determinação, que consiste em passar de categorias menos sustentáveis para categorias mais sustentáveis, mas ainda não conclusivas. Este procedimento é denominado por Hartmann de "progressão intraesférica". Tarefa da dialética é, então, vincular ambas as progressões, ou seja, percorrer, linearmente, a progressão arquitetônica e a progressão intraesférica e as "passagens" têm, nos dois casos, continuidade linear e plausibilidade diferenciadas.

Para Hartmann, a dialética, enquanto opção ontológica, por um lado, conserva a imanência subjetiva da filosofia transcendental de Kant e Fichte: o fundamento da dialética é uma subjetividade, o absoluto enquanto idéia absoluta, cujos antecedentes são legitimados. Por outro lado, possibilita uma ontologia, que não é condicionada pelo sujeito finito, que se defende frente a propostas alternativas. A subjetividade é ontologicamente recuperada e com isto o fundamento de validade da ontologia categorial.

\section{4 - Ontologia(lógica) e filosofia do real}

Hegel divide, então, sua filosofia, enquanto doutrina das categorias, em lógica e filosofia do real. Com isto se dá conta da alteridade da realidade em relação ao conceito para além da lógica, mas também é feito compreensivel através da lógica, como é que as categorias da lógica podem ser princípios da exterioridade. $\mathrm{O}$ importante, aqui, é que, também, a filosofia do real é ontologia.

Para Hartmann, a divisão hegeliana é uma solução original para o problema da relação entre metafísica geral e especial. Ela distingue claramente entre categorias "universais" e categorias "regionais" precisamente porque estas pressupõem natureza ou exterioridade, mas Hegel já exige categorialidade no nivel da lógica, onde temas da metafísica especial (Espirito, Deus, natureza) ${ }^{54}$ emergem em forma prévia universal. Hegel distingue, então, uma tríplice categorialidade: principial (lógica), relativa (filosofia da natureza, estádios subjetivo e objetivo da filosofia do espírito) e absoluta (espírito absoluto na filosofia do espírito).

No entanto, com isto, segundo Hartmann, o problema da relação entre lógica e filosofia do real não se solucionou plenamente, pois se pode trazer outras pers-

53 Cf. HARTMANN Kki, Hegel, op. cit. p. 111: “[...] a movement from species to genus is merely a movement to higher abstractions, unsupprted by the archtectonic. Accordingly, such a movement, though supercially similar to Hegel's dialectic, cannot be an ontology of thought as the ground for categories".

54 É uma questão discutida entre os intérpretes, se Hegel, já, na Lógica, se refere aos temas regionais. Cf. a respeito: LITT T., Hegel, Heidelberg, 1953, p. 248 e ss. 
pectivas de interpretação. ${ }^{65}$ Por exemplo, há quem afirme que, no caso da filosofia do real não se trata de uma teoria das categorias ou, pelo menos, não só disto, mas de uma metafísica que põe o ser enquanto existente ou que, no caso da filosofia do real, se deve recorrer, além da referência a princípios de uma aprioridade mais abstrata, a outro principiado que só parcialmente se deixa captar em categorias. ${ }^{56}$

Para Hartmann é claro que é necessário percorrer, através de categorias e num discurso imanente a elas, as esferas do real, porque as categorias são a articulação conceitual do que o real é. Nós estariamos na esfera do pensamento representativo $^{57}$ se imaginássemos que seria necessário acolher um "verdadeiramente outro" enquanto determinante do conceito na interpretação da determinidade do conceito do real. A reconstrução que, aqui, é exigida, só pode introduzir um outro, expresso pela mediação do conceito, enquanto determinante do conceito, o que leva Hartmann a dar razão a W. Cramer e H. Wagner ao afirmarem que o conhecimento é a posição de objetos enquanto não postos. Porém, para Hartmann isto não só não impede, mas antes implica que uma doutrina das categorias tenha que pôr o que o que é posto como não posto, ou seja, enquanto em si. Numa palavra, o outro, que a dialética conhece, é o outro "compreendido" enquanto outro, portanto, articulado conceitualmente.

No entanto, para ele, Hegel não foi fiel a esta concepção estrita de filosofia do real, uma vez que ele co-dialetizou a revelação cristã, a encarnação de Cristo, ou seja, introduziu, na doutrina das categorias, a posição de existência de um indivíduo, já que Hegel reconhece a prova da existência de Deus enquanto indivíduo metafísico, para o qual o mundo é ideal e que para o mundo é ideal. Aqui, Hegel fere o ponto de vista de uma ontologia categorial, que não põe referência particular, ou não põe existência alguma, mas apenas a exige a fim de que o título categorial não seja vazio. Hegel supera, assim, uma ontologia categorial na direção da metafísica, um ponto de vista que é abandonado no pensamento conclusivo do sistema, que não é indivíduo: Deus, que fora concebido como o absoluto na forma

55 L. B. Puntel, por exemplo, fala de "ampliação" do sentido das categorias da lógica na filosofia do real. Cf.: PUNTEL L. B., Darstellung, Methode und Struktur. Untersuchungen zur Einheit der systemathischen Philosophie G. W. F. Hegels, seg. ed., Bonn, 1981, p. 53. Cirne Lima, por sua vez, recorre ao mecanismo lógico da reduplicação para tornar compreensivel a distinção hegeliana. Cf.: CIRNE LIMA C. R. V., A lógica do Absoluto, in: Sintese Nova fase 63 (1993) p. 516 e ss.

56 Para Hartmann, esta é precisamente a posição de $\mathrm{H}$. Wagner, que, aqui, de certo modo, assume a posição de N. Hartmann, de uma identificação apenas parcial das categorias do ser e das categorias do conhecer. Para H. Wagner, os conceitos que determinam o pensamento(as condições lógicas do pensamento) enquanto "aprioridade primário-constitutiva", contêm indicações a um objeto, que devem ser explicitadas com outros princípios, a "aprioridade secundário-constitutiva". São estes conceitos que devem tomar possivel o conhecimento do em si do objeto, no entanto, o em si só é, propriamente, explicitado, quando é acrescentado um irracional, que é posto para além do que é articulado através dos conceitos. Para Hartmann, tal postura se contrapõe, radicalmente, à postura do ponto de vista categorial. Cf.: HARTMANN KJ., Die ontologische Option, op. cit. p. 14.

57 Com isto, estaríamos negando a mediação transcendental intranscendivel em todo conhecimento, o que a filosofia dialética, em princípio, não nega, mas, ao contrário, leva às últimas conseqüências. 
da representação, é ultrapassado na direção de uma última idealidade, que se poderia chamar "categorialidade do mundo". 58

Para Hartmann, muito fecunda é a filosofia hegeliana do espírito objetivo, porque consegue pensar a partir de categorias o que antes era visto apenas como agregado de sujeitos, ou seja, enquanto conceitos de unidade que contêm um "universal concreto". ${ }^{59}$ Seu grande mérito, com a perspectiva categorial, é superar o nominalismo no campo social: o campo do espírito objetivo contém figuras de positividade social. Esta categorização é, contudo, pensada de forma diferenciada de acordo com a pluralização de sujeitos frente a uma coisa (contrato) e frente a outros sujeitos (eticidade na esfera da família, sociedade, corporação e Estado).

Para Hartmann precisamente esta concepção do universal concreto substitui exigências éticas em relação ao indivíduo através do estabelecimento de figuras, ontologicamente diagnostizáveis ou estados de coisas relacionais, como aliás Aristóteles teria feito de forma não categorial. Claro que é sempre possivel e até necessário um tratamento empírico de toda esta problemática. No entanto, o mérito de Hegel é ter mostrado que se pode inserir o campo social numa ontologia normativa, ordenada categorialmente e não apenas trabalhá-la sociologicamente, isto é, de um ponto de vista nominalista. ${ }^{60}$

$\mathrm{Kl}$. Hartmann é consciente de que esta concepção de ontologia categorial, em Hegel, contém, do ponto de vista metodológico, um problema sério, pois o método dialético, como Hegel o concebe, implica um desenvolvimento linear de todas as categorias recebidas de acordo com a perspectiva da falta de pressupostos assim que não se pode recorrer ao que ainda não foi fundamentado. No entanto, no caso de formações sociais na filosofia do espírito, a questão é que, por um lado, elas têm que ser ordenadas linearmente de tal modo que de um antecedente se passe logicamente para um conseqüente, como, por exemplo, do direito abstrato para a moralidade, mas, por outro lado, vale contra o procedimento linear, que formações, realmente coexistentes, dizem respeito a diferentes graus de categorização, assim, por exemplo, a familia no estado é outra coisa, como é o caso, também, da sociedade. Não é, contudo, possível, do ponto de vista metodológico, antecipar a correção no degrau em questão, já que é, precisamente, a deficiência do degrau que vai conduzir o processo de exposição categorial para frente. Isto significa dizer que as considerações categoriais sobre a familia, a sociedade e o Estado são corretas, mas a exposição do concreto permanece deficiente e exige uma reflexão posterior sobre a coexistência de categorias de diferentes niveis. ${ }^{61}$

${ }^{58}$ Cf.: HARTMANN K1., Die ontologische Option, op. cit. p. 19.

59 Cf. a respeito: OLIVEIRA M. A de, A teoria marxiana situada na tradição do pensamento transcendental, in: A filosofia na crise da modernidade, São Paulo, 1989, p. 61-72; Filosofia política: de Hobbes a Marx, in: Ética e Sociabilidade, São Paulo, 1993, p. 106-109.

60 Cf.: HARTMANN Kl., Sartres Sozialphilosophie, Berlin, 1966, sobretudo pg. 135 e ss, 140-144.

${ }_{61}$ A partir desta problemática, Kl. Hartmann acha conveniente relacionar a filosofia do direito de Hegel com a teoria sociológica dos sistemas. Cf.: HARTMANN Kl., Die ontologische Option, op. cit. p. 23. 


\section{5 - Filosofia categorial e História}

Para Kl. Hartman, pode-se, em primeiro lugar, dizer que a filosofia hegeliana contém uma referência à história no sentido de que Hegel assume um ponto de vista "entelequial", que afirma poder ser um inventário de categorias plenamente racionalizável. No entanto, a filosofia hegeliana é histórica num outro sentido: Hegel tentou interpretar dialeticamente tanto em sua filosofia da história, como em sua filosofia da religião e na estética , a progressão temporal do espirito na história enquanto progressão do Estado, da captação filosófica da realidade, da relação entre o homem e Deus e da relação entre o homem e a obra de arte. Nesta perspectiva, por exemplo, a filosofia do direito, enquanto resultado de uma dialética histórica, seria dependente de uma dialetização da história. A mesma coisa valeria para as outras lições de Hegel, a filosofia da religião, da arte, etc.

Para Hartmann, tal procedimento enquanto dialetização da progressão histórica e com isto do tempo histórico não é mais ontologia categorial, mas pura e simplesmente metafísica, pois, aqui, são tratados, enquanto progressōes de idéias fundamentáveis, acontecimentos que se sucedem, eventos das formas de Estado, concepções filosóficas, religiões, expressões artísticas, numa palavra, seres existentes. A progressão temporal pára no respectivo nível categorial, não conduz, contudo, como é o caso na dialética sistemática, através de uma série de categorias, a uma conclusão que seja fundamento de validade das categorias. Esta forma de dialética não possui uma justificação como é o caso da filosofia categorial. Para Hartmann, uma opção filosófica rigorosa e capaz de fundamentar-se é a ontologia categorial. Por esta razão, o único que, aqui, se pode fazer é tomar distância de tal forma da metafísica, porque insustentável.

É a partir do mesmo ponto de vista fundamental que Kl. Hartmann toma posição em relação à dialética marxiana. ${ }^{62}$ Em primeiro lugar, Kl. Hartmann interpreta o pensamento de Marx como a apresentação da autogênese do homem, onde se manifesta que desenvolvimentos históricos possuem uma significação sistemática. Ora, para Hartmann, aqui está a marca característica do pensamento de Marx: a mistura entre história e sistemática.

Além disto, existe uma outra questão que toca a raiz mesma do pensamento dialético. A dialética hegeliana é uma teoria da fundamentação, pois a última categoria é fundamento de validade de todas as categorias anteriores. Marx não pretende chegar a uma afirmação última, mas sua intenção é critica. Sua teoria não é de fundamentação última, mas pretende ser uma teoria crítica, isto é, negativa. Neste caso, o resultado não legitima todos os passos anteriores da teoria. Onde se legitima, então, esta teoria? Não há uma resposta possivel a esta questão no pensamento de Marx. A dialética é, fundamentalmente, um método de fundamentação, ${ }^{63}$ o que ela não pode ser em Marx em virtude da própria natureza da teoria. Dialética, para Kl. Hartmann, é, acima de tudo, ontologia categorial e é neste sentido de uma filosofia fundamental que ela pode exercer uma função critica.

62 Cf.: HARTMANN Kl., Die Marxsche Theorie, op. cit. Oliveira M.A de, A teoria marxiana situada na tradição transcendental, op: cit.

${ }^{63}$ Cf. a respeito de uma crítica a esta pretensão: DOMINGUES I., A questão da fundamentação última em filosofia, in: Kriterion 91(1995)29-44. 